\title{
The ordered weighted average inflation
}

Ernesto León-Castro ${ }^{1}$, Luis F. Espinoza-Audelo² , José M. Merigó $^{3,4}$, Anna M. GilLafuente $^{5}$, Ronald R. Yager ${ }^{6}$

${ }^{1}$ Universidad De La Salle Bajio Av Universidad 602 Lomas del Campestre C.P. 37150 León, Guanajuato, Mexico

${ }^{2}$ Universidad of Occidente, Blvd. Lola Beltrán s/n esq. Circuito Vial, Culiacán 80200, México

${ }^{3}$ School of Systems, Management and Leadership, Faculty of Engineering and Information Technology, University of Technology Sydney, Ultimo, 2007 NSW, Australia

${ }^{4}$ Department of Management Control and Information Systems, School of Economics and Business, University of Chile, Av. Diagonal Paraguay 257, 8330015 Santiago, Chile

${ }^{5}$ Department of Business Administration, University of Barcelona, Av. Diagonal 690, 08034 Barcelona, Spain

${ }^{6}$ Machine Intelligence Institute, Iona College, New Rochelle, New York, USA

\begin{abstract}
This paper introduces the ordered weighted average inflation (OWAI). The OWAI operator aggregates the information of a set of inflations and provides a range of scenarios from the minimum and the maximum inflation. The advantage of this approach is that it can provide a flexible inflation formula that can be adapted to the specific characteristics of the enterprise, region, state or country. Therefore, the novelty of this operator is that experts can forecast the information and provide optimistic or pessimistic results of the expected average inflation according to the knowledge, aptitude or expectations for the whole country or an event that represents a specific sector, market or industry. The paper develops several extensions by using the induced, heavy and prioritized aggregation operators. The work studies the applicability of the operator to the analysis of Mexican inflation by developing some aggregation systems that consider the average inflation of Mexico.
\end{abstract}

Keywords: inflation; induced aggregation operators; economics, Mexico.

\footnotetext{
${ }^{1}$ Corresponding author

Emails: eleon@ucsc.cl ; luis.espinoza@udo.mx; jmerigo@fen.uchile.cl; amgil@ub.edu; yager@panix.com
} 


\section{Introduction}

Inflation has been an interest for countries since Friedman's [1] novel lecture about the relationship between inflation and growth and how the uncertainty in the first one can affect the second one, arguing that the noise in the price systems that is caused by economic institutions and factors reduces the economic efficiency and affects other variables such as employment and enterprise performance [2-3].

Because of these, policy makers in every country are usually willing to trade some shortterm losses in order to have price stability [4]. Additionally, because of the relation between growth and inflation [5-7], many countries have policies that focus on inflation targets that can be either intervals or a point target and are usually based on the central bank's internal information [8-9]. In this sense, the formulation for targeting inflation is very important [10-11], and the use of a formulation that can include the historical data and the expectations will be important.

Among the aggregation operators, one of the most used and studied ones is the Ordered Weighted Average (OWA) operator that was developed by Yager [12]. This operator aggregates several inputs that lie between the maximum and minimum operators. Additionally, some extensions have been developed [13], such as the induced OWA (IOWA) operator [14] that uses induced values that are provided by the decision maker in the reordering process between the weights and the arguments instead of the maximum or minimum criteria, the heavy OWA (HOWA) operator [15] that instead uses an unbounded weighting vector that will help to over- or underestimate the results according to different qualitative elements obtained by the decision maker, the prioritized OWA (POWA) operator [16] that is very useful when the problem seeks to unify the ideas of different decision makers and not everyone has the same importance assigned to the result, among other extensions. In recent years, aggregation operators have been applied to different economic and financial problems such as stock markets [17], exchange rates [18-19], price analysis [20], enterprise risk management [21], government transparency [35] and many more.

The main motivation for studying inflation using aggregation operators is that this important economic variable is not the same for every country, and not all countries use the 
same categories or the same weights, thus making the comparison process difficult. In addition, when inflation is published by the Central Banks, this information is based on the weights that are determined by them; however, sometimes, this scenario does not reflect the specific scenario for the companies. In this sense, the idea of using different weights and induced values becomes relevant to understanding the reality of a specific market/sector. As can be seen, there is a gap between the information that want to be provided by the government and the real inflation that a specific case can have, in this sense, it is possible to adequate the results based on the weighting vector, that is because most of the countries calculate their inflation based on a weighted average (WA) operator, where they have some product/service divisions that are multiplied by a weight according to their importance in the specific country. In this sense, the basic idea of inflation can be improved by the OWA operator proposed by Yager (1988) and more scenarios can be obtained.

Most of the countries calculate their inflation based on a weighted average (WA) operator, $t$ This paper presents the Ordered Weighted Average Inflation (OWAI) operator. An interesting way to calculate and present the inflation is to calculate the maximum and the minimum inflation. This idea is important because when inflation is calculated, usually the government tends to focus on the items that have higher weights in the formulation and then ignore the others with lower importance to the final score. This generates conflicts within countries since sometimes purchasing power is lower than the inflation indicates. That is why the idea of generating the minimum and the maximum inflation can better explain the reality of the country or the sector of the economy that is to be analyzed.

Additionally, some extensions of the OWAI operator combined with prioritized, induced and heavy operators are introduced. This new aggregation operator is called the prioritized induced heavy ordered weighted average inflation (PIHOWAI) operator, and this operator can be obtained as special cases of the induced heavy ordered weighted average inflation (IHOWAI), induced ordered weighted average inflation (IOWAI), heavy ordered weighted average nflation (HOWAI), prioritized ordered weighted average inflation (POWAI) and OWAI operators. These special cases can be used when the formulation does not need all of the information that the PIHOWAI operator needs. In this sense, when the problem is not that complex, it is possible to use a more simplified form of the operator. Additionally, it is important to note that there are 4 different cases when using the PIHOWAI operator that 
include the total operator in which the OWA operator and its extension are used in all the elements that compose the formula of case 3 where it is only used in the final formula. Finally, an example assessing Mexican inflation in 2017 using the PIHOWAI operator with three experts was given to provide new ranges of inflation in the country compared with the usual formula that is provided by the National Institute of Statistics and Geography (INEGI is its acronym in Spanish).

The remainder of this paper is organized as follows. In section 2, a revision of the basic formulations of inflation and the OWA are presented. Section 3 presents the general idea of the OWAI operator, the particular case of Mexico and a numerical example. Section 4 analyzes the inflation in Mexico for 2017 using different aggregation operators, and section 5 summarizes the main conclusions of the paper.

\section{Preliminaries}

\subsection{Inflation formula}

Depending on the country, the inflation formula is different with respect to the elements that compose the formula, but, in a general sense, the idea is the same. In the case of Mexico, the formulation is as follows [22]. ${ }^{2}$

Definition 1. In Mexico, the calculation for inflation is as follows:

$$
\text { Inflation }=\left[(0.75)\left(I_{s}\right)\right]+\left[(0.25)\left(I_{n s}\right]\right.
$$

where $I_{S}$ is the subjacent inflation ${ }^{3}$ and $I_{n s}$ is the nonsubjacent inflation ${ }^{4}$.

Definition 2. $I_{S}$ is defined as

$$
I_{s}=\left[(0.47)\left(I_{m}\right)\right]+\left[(0.53)\left(I_{s e}\right)\right]
$$

where $I_{m}$ is merchandise inflation and $I_{s e}$ is the services inflation. $I_{m}=$ $\left(\frac{C P I_{n}-C P I_{n-1}}{C P I_{n-1}}\right)(100)$, and $C P I$ is the consumer price index ${ }^{5}$. The same formulation applies to $I_{S e}$.

Definition 3. $I_{n s}$ is defined as

$$
I_{n s}=\left[(0.37)\left(I_{a}\right)\right]+\left[(0.63)\left(I_{e}\right)\right]
$$

\footnotetext{
${ }^{2}$ The parameter values assigned to $I_{S}$ and $I_{n s}$ are the official ones that are used by the Mexican government.

${ }^{3}$ Subjacent inflation is the concept that refers to the evolution of the prices of a representative basket of consumer goods and services from which energy products and unprocessed foods are excluded.

${ }^{4}$ Non-subjacent inflation is the concept that refers to the evolution of the prices of energy products and unprocessed foods.

${ }^{5}$ The Consumer Price Index (CPI) is a measure of the average change over time in the prices that are paid by urban consumers for a market basket of consumer goods and services.
} 
where $I_{a}$ is the agricultural inflation and $I_{e}$ is the energetics and government inflation. It is important to note that $I_{a}=\left(\frac{C P I_{n}-C P I_{n-1}}{C P I_{n-1}}\right)(100)$, and the same formulation is applied to $I_{e}$.

\subsection{OWA operator and its extensions}

A technique that helps to provide new scenarios based on the maximum and the minimum operators is the OWA operator [12]. The formulation is as follows:

$$
O W A\left(a_{1}, a_{2}, \ldots, a_{n}\right)=\sum_{k=1}^{n} w_{j} b_{j},
$$

where $b_{j}$ is the $j$ th element that is the largest of the collection $a_{1}, a_{2}, \ldots, a_{n} . w=$ $\left[w_{1}, w_{2}, \ldots, w_{n}\right]^{T}$, where $w_{j} \in[0,1], 1 \leq i \leq n$ and

$$
\sum_{i=1}^{n} w_{j}=w_{1}+w_{2}+\cdots+w_{n}=1 .
$$

In group decision making [36-37], there are cases where the members in the decision process do not assign the same weights to the final results. In this sense, some components have more impact on the final results than others, and this can be because of the experience, hierarchical level and many other quantitative or qualitative aspects. To aggregate the information in an optimal way, the prioritized OWA (POWA) operator [16] can be used. The formulation is as follows.

Definition 4. Assume that we have a collection of criteria that are portioned into $q$ distinct groups, $H_{1}, H_{2}, \ldots, H_{q}$, where $H_{i}=\left\{C_{i 1}, C_{i 2}, \ldots, C_{i n_{i}}\right\}$ denotes the criteria of the $i$ th category $(i=1, \ldots, q)$ and $n_{i}$ is the number of criteria in the class. Furthermore, we have a prioritization between the groups as $H_{1}>H_{2}>\cdots>H_{q}$. That is, the criteria in the category $H_{i}$ have a higher priority than those in $H_{k}$ for all $i<k$ and $i, k \in\{1, \ldots, q\}$. Denote the total set of criteria as $C=U_{i=1}^{q} H_{i}$ and the total number of criteria as $n=$ $\sum_{i=1}^{q} n_{i}$. Additionally, suppose that $X=\left\{x_{1}, \ldots, x_{m}\right\}$ indicates the set of alternatives. For a given alternative $x$, let $C_{i j}(x)$ measure the satisfaction of the $j$ th criteria in the $i$ th group by alternative $x \in X$ for each $i=1, \ldots, q$ and $j=1, \ldots, n_{i}$. The formula is as follows:

$$
C_{(x)}=\sum_{i=1}^{q} \sum_{h=1}^{n_{i}} w_{i j} C_{i j}(x),
$$


where $w_{i j}$ is the corresponding weight of the $j$ th criteria in the $i$ th category; $i=$ $1, \ldots, q$; and $j=1, \ldots, n_{i}$.

Another extension of the OWA operator is the induced OWA (IOWA) operator [14]. This operator has as the main characteristic that the weights are associated based on induced values instead of the maximum or the minimum operator. The formulation is as follows:

$$
\operatorname{IOWA}\left(\left\langle u_{1}, a_{1}\right\rangle,\left\langle u_{2}, a_{2}\right\rangle, \ldots,\left\langle u_{n}, a_{n}\right\rangle\right)=\sum_{j=1}^{n} w_{j} b_{j},
$$

where $b_{j}$ is the $a_{i}$ value of the OWA pair $<u_{i}, a_{i}>$ having the $j$ th largest $u_{i}, u_{i}$ is the order-inducing variable, and $a_{i}$ is the argument variable.

The heavy OWA (HOWA) operator [15] is an aggregation operator where the weighting vector is unbounded instead of being equal to one (like in the OWA operator case). This characteristic helps to under- or overestimate based on the expectations and aptitude of the decision maker. The definition is as follows.

Definition 5. A heavy aggregation operator is an extension of the OWA operator for which the sum of the weights is bounded by $n$. Thus, a HOWA operator is a mapping $R^{n} \rightarrow R$ that is associated with a weight vector $w$, where $w_{j} \in[0,1]$ and $1 \leq$ $\sum_{j=1}^{n} w_{j} \leq n$, such that the following holds:

$$
\operatorname{HOWA}\left(a_{1}, a_{2}, \ldots, a_{n}\right)=\sum_{j=1}^{n} w_{j} b_{j},
$$

where $b_{j}$ is the $j$ th largest element of the collection $a_{1}, a_{2}, \ldots, a_{n}$ and the sum of the weights $w_{j}$ is bounded by $n$ or can be unbounded if the weighting vector $W$ is $-\infty \leq$ $\sum_{j=1}^{n} w_{j} \leq \infty$.

The prioritized induced heavy OWA (PIHOWA) operator is an aggregation operator that can be used in a group decision making process where not all the decision makers are equally important, and it uses an unbounded weighting vector and an ordering based on the induced values. The formulation is as follows. 
Definition 6. A PIHOWA operator of dimension $n$ is a mapping PIHOWA: $R^{n} x R^{n} \rightarrow R$ that has an associated weight vector $w$ of dimension $n$, where $w_{j} \in[0,1]$ and $1 \leq$ $\sum_{\mathrm{j}=1}^{\mathrm{n}} \mathrm{w}_{\mathrm{j}} \leq \mathrm{n}$, such that

$$
\operatorname{PIHOWA}\left(\left\langle u_{1}, a_{1}\right\rangle,\left\langle u_{2}, a_{2}\right\rangle, \ldots,\left\langle u_{n}, a_{n}\right\rangle\right)=\sum_{i=1}^{q} \sum_{h=1}^{n_{i}} b_{j} \hat{v}_{i j} C_{i j}(x),
$$

where $b_{j}$ is the $j$ th element that has the largest $u_{i} ; u_{i}$ is the induced order of variables; $\hat{v}_{i j}$ is the corresponding weight of the $j$ th criteria in the $i$ th category; $i=1, \ldots, q ; j=1, \ldots, n_{i}$; and $C_{i j}(x)$ measures the satisfaction of the $j$ th criteria in the $i$ th group by alternative $x \in X$ for each $i=1, \ldots, q$ and $j=1, \ldots, n_{i}$. It is important to note that sometimes the weighting vector can be measured as $-\infty \leq \sum_{\mathrm{j}=1}^{\mathrm{n}} \mathrm{w}_{\mathrm{j}} \leq \infty$.

Some of the particular cases of the PIHOWA operator are as follows:

1) if $u_{i}=1 / n$, the PIHOWA operator becomes the PHOWA operator;

2) if $\sum_{\mathrm{j}=1}^{\mathrm{n}} \mathrm{w}_{\mathrm{j}}=1$, the PIHOWA operator becomes the PIOWA operator; and

3 ) if $C_{i j}(x)=1 / n$, the PIHOWA operator becomes the IHOWA operator.

\section{The ordered weighted average inflation}

\section{The ordered weighted average inflation}

The use of a combination of inflations with OWA operators will provide a new range of results based on the maximum and the minimum operators. These new results can help to provide a better understanding of the problem and establish better policies and actions to help the general economy of the country. Additionally, the practical advantage of the use of the OWA operator to calculate inflation is that it can be adapted to the needs of the market/sector/company. For example, usually, if a company wants to know the specific inflation rate for the construction sector or the agricultural sector to calculate new prices and policies for the company, the traditional inflation formula does not reflect that specification, but with the use of aggregation operators such as the OWA operator, a more accurate result can be obtained. The main problem that these new formulations try to solve is the little flexibility that the traditional formulation has and how it doesn't represent specific cases. As can be seen in formula 1 to 3 , there is a specific weight for each component in the formulation, but there are cases where some product/service divisions will be more important that others and by using the idea of the OWA operator new 
scenarios based on an specific industry/enterprise/decision makers that will improve the decision making process.

The Ordered Weighted Average Inflation (OWAI) operator that can be used as a base in order to be adapted to the specific formulation of each country is as follows.

Definition 7. The OWAI operator of dimension $n$ is a mapping $F: R^{n} \rightarrow R$ with a weight vector $w=\left[w_{1}, \ldots, w_{n}\right]^{T}$, where $w_{j} \in[0,1], 1 \leq i \leq n$ and $\sum_{i=1}^{n} w_{j}=w_{1}+\cdots+w_{n}=1$, and it can be defined as

$$
\operatorname{OWAI}\left(i_{1}, i_{2}, \ldots, i_{n}\right)=\sum_{k=1}^{n} w_{j} h_{j}
$$

where $h_{j}$ is the $j$ th element, which is the largest of the collection $i_{1}, i_{2}, \ldots, i_{n}$, and each element of the collection represents a set of inflation rates that are used in order to obtain the average inflation.

Additionally, by using order induced variables, it is possible to generate the Induced Ordered Weighted Average Inflation (IOWAI), and its definition is as follows.

Definition 8. The IOWAI operator of dimension $n$ is a mapping IOWAI: $R^{n} \times R^{n} \rightarrow R$ that has an associated weighting vector $W$ of dimension $n$, where the sum of the weights is 1 , $w_{j} \in[0,1]$, and an induced set of ordering variables is included $\left(u_{i}\right)$. The formula is

$$
\operatorname{IOWAI}\left(\left\langle u_{1}, i_{1}\right\rangle, \ldots,\left\langle u_{n}, i_{n}\right\rangle\right)=\sum_{k=1}^{n} w_{j} h_{j},
$$

where $h_{j}$ is the $a_{i}$ value of the OWA pair $\left\langle u_{i}, i_{i}>\right.$ having the $j$ th largest $u_{i} . u_{i}$ is the order-inducing variable, and $a_{i}$ is the inflation set.

Another extension can be provided by using unbounded vectors. In this sense, the Heavy Ordered Weighted Average Inflation (HOWAI) operator is presented.

Definition 9. The HOWAI operator is a mapping $R^{n} \rightarrow R$ that is associated with a weight vector $w$, where $w_{j} \in[0,1]$ and $1 \leq \sum_{j=1}^{n} w_{j} \leq n$, such that

$$
\operatorname{HOWAI}\left(i_{1}, i_{2}, \ldots, i_{n}\right)=\sum_{k=1}^{n} w_{j} h_{j}
$$


where $h_{j}$ is the $j$ th largest element of the collection $i_{1}, i_{2}, \ldots, i_{n}$ and the sum of the weights $w_{j}$ is bounded by $n$ or can be unbounded if the weighting vector $W$ is $-\infty \leq$ $\sum_{j=1}^{n} w_{j} \leq \infty$.

In group decision making where not all the members are equally important to the final results, the Prioritized Ordered Weighted Average Inflation (POWAI) operator is applied as follows.

Definition 10. Assume that we have a collection of criteria that are portioned into $q$ distinct groups, $H_{1}, H_{2}, \ldots, H_{q}$, where $H_{e}=\left\{C_{e 1}, C_{e 2}, \ldots, C_{e n_{i}}\right\}$ denotes the criteria of the eth category $(e=1, \ldots, q)$ and $n_{i}$ is the number of criteria in the class. Furthermore, we have a prioritization between the groups of $H_{1}>H_{2}>\cdots>H_{q}$. That is, the criteria in category $H_{e}$ have higher priority than those in $H_{k}$ for all $e<k$ and $e, k \in\{1, \ldots, q\}$. Denote the total set of criteria as $C=U_{e=1}^{q} H_{e}$ and the total number of criteria as $n=\sum_{e=1}^{q} n_{i}$. Additionally, suppose that $X=\left\{x_{1}, \ldots, x_{m}\right\}$ indicates the set of alternatives. For a given alternative $x$, let $C_{e j}(x)$ measure the satisfaction of the $j$ th criteria in the $e$ th group by alternative $x \in X$ for each $i=1, \ldots, q$ and $j=1, \ldots, n_{i}$. The formula is as follows:

$$
\operatorname{POWAI}\left(i_{1}, i_{2}, \ldots, i_{n}\right)=\sum_{e=1}^{q} \sum_{h=1}^{n_{i}} w_{e j} C_{e j}(x)
$$

where $w_{e j}$ is the corresponding weight of the $j$ th criteria in the eth category, $e=$ $1, \ldots, q$, and $j=1, \ldots, n_{i}$.

Finally, a combination of the three operators can be constructed in order to be used in complex situations. That is, an inflation formula with an aggregation operator that is unbounded with induced variables and with a group of decision makers with different importances can be used. The Prioritized Induced Heavy Ordered Weighted Average Inflation (PIHOWAI) operator is formulated as follows.

Definition 11. A PIHOWAI operator of dimension $n$ is a mapping PIHOWAI: $R^{n} x R^{n} \rightarrow R$ that has an associated weight vector $w$ of dimension $n$, where $w_{j} \in[0,1]$ and $1 \leq$ $\sum_{\mathrm{j}=1}^{\mathrm{n}} \mathrm{w}_{\mathrm{j}} \leq \mathrm{n}$, such that

$$
\operatorname{PIHOWAI}\left(\left\langle u_{1}, i_{1}\right\rangle,\left\langle u_{2}, i_{2}\right\rangle, \ldots,\left\langle u_{n}, i_{n}\right\rangle\right)=\sum_{e=1}^{q} \sum_{j=1}^{n_{i}} h_{j} \hat{v}_{e j} C_{e j}(x),
$$


where $h_{j}$ is the $j$ th inflation set that has the largest $u_{i} ; u_{i}$ is the induced ordering of variables; $\hat{v}_{e j}$ is the corresponding weight of the $j$ th criteria in the eth category; $i=$ $1, \ldots, q ; j=1, \ldots, e_{i}$; and $C_{e j}(x)$ measures the satisfaction of the $j$ th criteria in the $e$ th group by alternative $x \in X$ for each $e=1, \ldots, q, j=1, \ldots, n_{i}$. It is important to note that sometimes the weighting vector can be measured as $-\infty \leq \sum_{\mathrm{j}=1}^{\mathrm{n}} \mathrm{w}_{\mathrm{j}} \leq \infty$.

The PIHOWAI operator has the same special cases as the PIHOWA operator, which are as follows.

1) if $u_{i}=1 / n$, the PIHOWAI operator becomes the PHOWAI operator;

2) if $\sum_{j=1}^{n} w_{j}=1$, the PIHOWAI operator becomes the PIOWAI operator; and

3) if $C_{e j}(x)=1 / n$, the PIHOWAI operator becomes the IHOWAI operator.

An interesting fact is that the inflation sets that are used in order to calculate the average inflation can vary from country to country. That is why the use of this general formulation can be modified in order to be used in a specific country, like with the case of Mexico that is presented in section 3.2 .

\subsection{Ordered weighted average inflation operator in Mexico}

In this section, we will provide the different inflation formulas that can be obtained using the formulation for Mexico. The main advantage of the application of the following operators is that they can be used to reflect the specific inflation for a market/sector/company. In this way, they can provide a better understanding of the situation and allow for making more accurate changes in sales prices and other internal policies than when using the traditional inflation formula. It is important to note that, based on the formulation, four different special cases can be formulated. To provide a better explanation, the formulations will be provided for the total case, and the other three cases will be explained in section 3.3, with a numerical example given in 3.4. Definitions 9 to 13 are used to present the specific formulations for Mexico that are as follows.

Definition 12. A Mexico OWAI (MexOWAI) operator of dimension $n$ is a mapping $F: R^{n} \rightarrow R$ with a weight vector $w=\left[w_{1}, \ldots, w_{n}\right]^{T}$, where $w_{j} \in[0,1], 1 \leq i \leq n$ and $\sum_{i=1}^{n} w_{j}=w_{1}+\cdots+w_{n}=1$, and it can be defined as 


$$
\operatorname{MexOWAI}\left(O W A I_{s}, O W A I_{n s}\right)=\sum_{k=1}^{n} w_{j} I_{j},
$$

where $I_{j}$ is the $j$ th element, which is the largest of the collection $O W A I_{s}, O W A I_{n s}$. It is important to note that in the formulation, an OWA operator has been used in $I_{s}$ and $I_{n s}$. In this sense, the formulations for both are as follows.

Definition 13. A subjacent OWAI $\left(O W A I_{s}\right)$ operator of dimension $n$ is a mapping $F: R^{n} \rightarrow$ $R$ with a weight vector $w=\left[w_{1}, \ldots, w_{n}\right]^{T}$, where $w_{j} \in[0,1], 1 \leq i \leq n$ and $\sum_{i=1}^{n} w_{j}=$ $w_{1}+\cdots+w_{n}=1$, and it can be defined as

$$
\operatorname{OWAI}_{s}\left(I_{m}, I_{s e}\right)=\sum_{k=1}^{n} w_{j} S_{j}
$$

where $S_{j}$ is the $j$ th element, which is the largest of the collection $I_{m}, I_{s e}$. In addition, $I_{m}=$ $\left(\frac{C P I_{n}-C P I_{n-1}}{C P I_{n-1}}\right)(100)$. The same formulation applies to $I_{s e}$.

Definition 14. A nonsubjacent OWAI (OWAI $n s$ ) operator of dimension $n$ is a mapping $F: R^{n} \rightarrow R$ with a weight vector $w=\left[w_{1}, \ldots, w_{n}\right]^{T}$, where $w_{j} \in[0,1], 1 \leq i \leq n$ and $\sum_{i=1}^{n} w_{j}=w_{1}+\cdots+w_{n}=1$, and it can be defined as

$$
\operatorname{OWAI}_{n s}\left(I_{a}, I_{e}\right)=\sum_{k=1}^{n} w_{j} N S_{j}
$$

where $N S_{j}$ is the $j$ th element, which is the largest of the collection $I_{a}, I_{e}$. It is important to note that $I_{a}=\left(\frac{C P I_{n}-C P I_{n-1}}{C P I_{n-1}}\right)(100)$, and the same formulation is applied to $I_{e}$.

Definition 15. Mexico's IOWAI (MexIOWAI) operator of dimension $n$ is a mapping MexIOWAI: $R^{n} \times R^{n} \rightarrow R$ that has an associated weighting vector $W$ of dimension $n$, where the sum of the weights is $1, w_{j} \in[0,1]$, and an induced set of ordering variables is included $\left(u_{i}\right)$. The formula is

$$
\operatorname{MexIOWAI}\left(\left\langle u_{1}, I O W A I_{s}\right\rangle,\left\langle u_{2}, I O W A I_{n s}\right\rangle\right)=\sum_{k=1}^{n} w_{j} I_{j},
$$

where $I_{j}$ is the $a_{i}$ value of the OWA pair $<u_{i}, a_{i}>$ having the $j$ th largest $u_{i} . u_{i}$ is the order-inducing variable, and $a_{i}$ is the argument variable for IOWAI,$I O W A I_{n s}$.

Definition 16. Mexico's HOWAI (MexHOWAI) operator is an extension of the OWAI operator for which the sum of weights is bounded by $n$. Thus, the MexHOWAI operator is 
a map $R^{n} \rightarrow R$ that is associated with a weight vector $w$, with $w_{j} \in[0,1]$ and $1 \leq$ $\sum_{j=1}^{n} w_{j} \leq n$, such that

$$
\operatorname{MexHOWAI}\left(\mathrm{HOWAI}_{s}, \mathrm{HOWAI} I_{n s}\right)=\sum_{k=1}^{n} w_{j} I_{j},
$$

where $I_{j}$ is the $j$ th element, which is the largest of the collection $\mathrm{HOWAI}_{s}, \mathrm{HOWAI}_{n s}$; and the sum of the weights $w_{j}$ is bounded by $n$ or can be unbounded if the weighting vector $W$ is $-\infty \leq \sum_{j=1}^{n} w_{j} \leq \infty$.

Definition 17. Mexico's POWAI (MexPOWAI) operator can be defined if we assume that we have a collection of criteria that are portioned into $q$ distinct groups, $H_{1}, H_{2}, \ldots, H_{q}$, where $H_{e}=\left\{C_{e 1}, C_{e 2}, \ldots, C_{e n_{i}}\right\}$ denotes the criteria of the eth category $(e=1, \ldots, q)$ and $n_{i}$ is the number of criteria in the class. Furthermore, we have a prioritization between the groups of $H_{1}>H_{2}>\cdots>H_{q}$. That is, the criteria in category $H_{e}$ have a higher priority than those in $H_{k}$ for all $e<k$ and $e, k \in\{1, \ldots, q\}$. Denote the total set of criteria as $C=$ $U_{e=1}^{q} H_{e}$ and the total number of criteria as $n=\sum_{e=1}^{q} n_{i}$. Additionally, suppose that $X=$ $\left\{x_{1}, \ldots, x_{m}\right\}$ indicates the set of alternatives. For a given alternative $x$, let $C_{e j}(x)$ measure the satisfaction of the $j$ th criteria in the eth group by alternative $x \in X$ for each $i=$ $1, \ldots, q$ and $j=1, \ldots, e_{i}$. The formula is as follows:

$$
\operatorname{MexPOWAI}\left(\mathrm{POWAI}_{s}, \mathrm{POWAI}_{n s}\right)=\sum_{e=1}^{q} \sum_{h=1}^{n_{i}} w_{e j} C_{e j}(x),
$$

where $w_{e j}$ is the corresponding weight of the $j$ th criteria in the eth category; $e=$ $1, \ldots, q, j=1, \ldots, n_{i}$.

Definition 18. Mexico's PIHOWAI (MexPIHOWAI) operator of dimension $n$ is a mapping PIHOWAI: $R^{n} x R^{n} \rightarrow R$ that has an associated weight vector $w$ of dimension $n$, where $w_{j} \in[0,1]$ and $1 \leq \sum_{\mathrm{j}=1}^{\mathrm{n}} \mathrm{w}_{\mathrm{j}} \leq \mathrm{n}$, such that

$$
\text { MexPIHOW AI }\left(\left\langle u_{1}, \text { PIHOWAIs }\right\rangle,\left\langle u_{2}, \text { PIHOWAI } I_{n s}\right\rangle\right)=\sum_{e=1}^{q} \sum_{h=1}^{n_{i}} I_{j} \hat{v}_{e j} C_{e j}(x),
$$

where $I_{j}$ is the $a_{i}$ value of the OWA pair $<u_{i}, a_{i}>$ having the $j$ th largest $u_{i} . u_{i}$ is the order-inducing variable; $a_{i}$ is the argument variable for $P I H O W A I_{s}, P I H O W A I_{n s} ; \hat{v}_{i j}$ is the corresponding weight of the $j$ th criteria in the eth category; $e=1, \ldots, q ; j=1, \ldots, n_{i}$; 
and $C_{e j}(x)$ measures the satisfaction of the $j$ th criteria in the eth group by alternative $x \in X$ for each $e=1, \ldots, q, j=1, \ldots, n_{i}$. It is important to note that sometimes the weighting vector can be measured as $-\infty \leq \sum_{\mathrm{j}=1}^{\mathrm{n}} \mathrm{w}_{\mathrm{j}} \leq \infty$.

The same particular cases that are explained in Definitions 8 and 13 can applied in this case.

1) if $u_{i}=1 / n$, the MexPIHOWAI operator becomes the MexPHOWAI operator;

2) if $\sum_{j=1}^{n} w_{j}=1$, the MexPIHOWAI operator becomes the MexPIOWAI operator; and

3) if $C_{i j}(x)=1 / n$, the MexPIHOWAI operator becomes the MexIHOWAI operator.

It is relevant to note that for the weighting vector, it is possible to use the actual weights that are proposed by the INEGI (2018) or it can be changed based on the expectations and knowledge of the decision maker. In this sense, the INEGI weighting vector can be assumed to be one expert and the use of a different weighting vector based on other information (such as the weights that are used in other countries) or a weighting vector based on the experience and expertise of the decision maker can be applied.

\subsection{Special cases for the MexOWAI operator}

As has been explained in section 3.1, it is possible to generate different inflation OWA cases based on which elements of the OWA operator are included or not. The formulations are as follows (Table 1).

Table 1. MexOWA operators and the cases

\begin{tabular}{|c|c|c|c|c|}
\hline Operator & Total & Case 1 & Case 2 & Case 3 \\
\hline MexOWAI & $\begin{array}{l}\text { Uses: } \\
O W A I_{s} \text { and } \\
O W A I_{n s} \text {. }\end{array}$ & $\begin{array}{l}\text { Uses: } \\
O W A I_{s} \text { and } \\
I_{n s} .\end{array}$ & $\begin{array}{l}\text { Uses: } \\
I_{s} \text { and } \\
O W A I_{n s} .\end{array}$ & $\begin{array}{l}\text { Uses: } \\
I_{s} \text { and } I_{n s}\end{array}$ \\
\hline MexIOWAI & $\begin{array}{l}\text { Uses: } \\
I O W A I_{s} \text { and } \\
I O W A I_{n s} \text {. }\end{array}$ & $\begin{array}{l}\text { Uses: } \\
I O W A I_{S} \text { and } \\
I_{n s} .\end{array}$ & $\begin{array}{l}\text { Uses: } \\
I_{s} \text { and } \\
I O W A I_{n s} .\end{array}$ & $\begin{array}{l}\text { Uses: } \\
I_{s} \text { and } I_{n s}\end{array}$ \\
\hline MexHOWAI & $\begin{array}{l}\text { Uses: } \\
H_{O W A I_{s}} \text { and } \\
H_{O W A I_{n s}} \text {. }\end{array}$ & $\begin{array}{l}\text { Uses: } \\
H O W A I_{s} \text { and } \\
I_{n s} .\end{array}$ & $\begin{array}{l}\text { Uses: } \\
I_{s} \text { and } \\
\text { HOWAI } I_{n s} .\end{array}$ & $\begin{array}{l}\text { Uses: } \\
I_{s} \text { and } I_{n s}\end{array}$ \\
\hline MexIHOWAI & Uses: & Uses: & Uses: & Uses: \\
\hline
\end{tabular}




\begin{tabular}{|c|c|c|c|c|}
\hline & $\begin{array}{l}I_{H O W A I_{S}} \text { and } \\
\text { IHOWAI }_{n s} \text {. }\end{array}$ & $\begin{array}{l}I H O W A I_{s} \text { and } \\
I_{n s} .\end{array}$ & $\begin{array}{l}I_{s} \text { and } \\
\text { IHOWAI }_{n s} .\end{array}$ & $I_{s}$ and $I_{n s}$. \\
\hline MexPOWAI & $\begin{array}{l}\text { Uses: } \\
P O W A I_{s} \text { and } \\
P O W A I_{n s} .\end{array}$ & $\begin{array}{l}\text { Uses: } \\
P O W A I_{s} \text { and } \\
I_{n s} .\end{array}$ & $\begin{array}{l}\text { Uses: } \\
I_{s} \text { and } \\
P O W A I_{n s} .\end{array}$ & $\begin{array}{l}\text { Uses: } \\
I_{s} \text { and } I_{n s} .\end{array}$ \\
\hline MexPIOWAI & $\begin{array}{l}\text { Uses: } \\
\text { PIOWAI }_{s} \text { and } \\
\text { PIOWAI }_{n s} \text {. }\end{array}$ & $\begin{array}{l}\text { Uses: } \\
\text { PIOWAI }_{s} \text { and } \\
I_{n s} .\end{array}$ & $\begin{array}{l}\text { Uses: } \\
I_{s} \text { and } \\
\text { PIOWAI } I_{n s} .\end{array}$ & $\begin{array}{l}\text { Uses: } \\
I_{s} \text { and } I_{n s} .\end{array}$ \\
\hline MexPHOWAI & $\begin{array}{l}\text { Uses: } \\
\text { PHOWAI }_{s} \text { and } \\
\text { PHOWAI }_{n s} \text {. }\end{array}$ & $\begin{array}{l}\text { Uses: } \\
\text { PHOWAI } \text { and } \\
I_{n s} .\end{array}$ & $\begin{array}{l}\text { Uses: } \\
I_{s} \text { and } \\
\text { PHOWAI } I_{n s} .\end{array}$ & $\begin{array}{l}\text { Uses: } \\
I_{s} \text { and } I_{n s} .\end{array}$ \\
\hline MexPIHOWAI & $\begin{array}{l}\text { Uses: } \\
\text { PIHOWAI }_{s} \text { and } \\
\text { PIHOWAI }_{n s} \text {. }\end{array}$ & $\begin{array}{l}\text { Uses: } \\
\text { PIHOWAI }_{s} \text { and } \\
I_{n s} \text {. }\end{array}$ & $\begin{array}{l}\text { Uses: } \\
I_{s} \text { and } \\
\text { PIHOWAI }_{n s} .\end{array}$ & $\begin{array}{l}\text { Uses: } \\
I_{s} \text { and } I_{n s} .\end{array}$ \\
\hline
\end{tabular}

The use of different special cases of the MexOWAI is important because it is possible to use different information according to the complexity of the year or the industry that we want to analyze. For example, if the enterprise that wants to analyze the inflation has an important impact on the nonsubjacent components, then the use of the case 2 operator is suggested. Like this, many more examples can be done by understanding that the most complex situation is the total operator and the least complex is case 3 . The main idea of presenting these special cases is that the decision-making process can be improved if more scenarios are analyzed and it consider the different decisions that involve inflation such as sales, costs, profit margins, salaries and many more.

Finally, these new formulations can be easily adopted by the decision maker because the traditional formulation already has the information needed to apply the reordering step between the argument and the weights. In this sense, instead of obtain new information or event more data to generate different scenarios and applied other aggregation operators, the main benefit of the OWA operator is that the traditional formulation used by many countries for calculate inflation is already a weighted average (WA) operator, because of that is easy to adjust the formula and obtain different results based on the maximum and minimum operator. Also, because of that it is possible to use any of the extensions of the OWA operator and not only the ones used in this paper. 


\section{Calculation of Mexico's inflation from January 2017 - December 2017}

In this section, the procedure to use the OWAI operator and its extensions is explained. The idea of using different aggregation operators that include information such as the knowledge, expectation, aptitude and expectations of the decision maker instead of the traditional formulation is that usually the traditional formulation is a generalization of many scenarios, but sometimes the result is not the best scenario for a specific company, decision maker or time. In this sense, the use of the OWA operator and its extensions provides different scenarios that can be more accurate or related to the decision makers knowledge. The steps to using the OWAI operators are detailed as follows.

Step 1. To visualize the monthly inflation and the annual inflation using the traditional formulation, the OWAI operator and its extensions, the data from December 2016 to December 2017 is used and presented in Table 2.

Step 2. In this example, three different experts were interviewed. In this sense, different vectors are used to calculate subjacent and non-subjacent inflation. The information is presented in Table $3^{6}$. Additionally, a prioritized vector $=(0.35,0.25,0.40)$ is used based on their expertise in the field.

Step 3. The inflation of each CPI is done using $\left(\frac{C P I_{n}-C P I_{n-1}}{C P I_{n-1}}\right)(100)$, that results are presented in Table 4.

Table 2. CPI information from December 2016 to December 2017 for Mexico

\begin{tabular}{ccccc}
\hline Date & CPI Merchandise & CPI Services & $\begin{array}{c}\text { CPI } \\
\text { agricultural }\end{array}$ & $\begin{array}{c}\text { CPI Energetics and } \\
\text { government }\end{array}$ \\
\hline $12-16$ & 123.53 & 116.02 & 136.95 & 130.73 \\
$01-17$ & 124.68 & 116.35 & 135.74 & 142.45 \\
$02-17$ & 126.06 & 116.90 & 134.47 & 143.29 \\
$03-17$ & 127.04 & 117.36 & 137.42 & 143.15 \\
$04-17$ & 127.80 & 117.73 & 139.99 & 139.69
\end{tabular}

\footnotetext{
${ }^{6}$ The weights are determined by the experts according to the impacts that they think the elements have in the sector where the enterprise works. Other techniques can be used, such as simple additive weighting [28] or the ones proposed by [29-31]
} 


\begin{tabular}{lllll}
$05-17$ & 128.42 & 117.85 & 141.68 & 135.75 \\
$06-17$ & 128.82 & 118.19 & 142.28 & 135.58 \\
$07-17$ & 128.97 & 118.66 & 145.82 & 135.03 \\
$08-17$ & 129.58 & 118.74 & 148.83 & 135.94 \\
$09-17$ & 130.01 & 119.02 & 148.73 & 136.91 \\
$10-17$ & 130.29 & 119.36 & 145.94 & 142.59 \\
$11-17$ & 130.73 & 119.78 & 147.63 & 148.64 \\
$12-17$ & 131.15 & 120.39 & 150.31 & 149.61 \\
\hline
\end{tabular}

Table 3. Weights assigned to subjacent and non-subjacent inflation

\begin{tabular}{|c|l|l|}
\hline Expert & Weights for subjacent inflation & Weights for non-subjacent inflation \\
\hline$e_{1}$ & $W_{1}=(0.45,0.55)$ & $W_{1}=(0.40,0.60)$ \\
& $H_{1}=(0.50,0.60)$ & $H_{1}=(0.45,0.65)$ \\
& $U_{1}=(10,5)$ & $U_{1}=(10,5)$ \\
\hline$e_{2}$ & $W_{2}=(0.60,0.40)$ & $W_{2}=(0.55,0.45)$ \\
& $H_{2}=(0.70,0.40)$ & $H_{2}=(0.60,0.50)$ \\
& $U_{2}=(5,10)$ & $U_{2}=(5,10)$ \\
\hline$e_{3}$ & $W_{3}=(0.53,0.47)$ & $W_{3}=(0.58,0.42)$ \\
& $H_{3}=(0.55,0.50)$ & $H_{3}=(0.60,0.45)$ \\
& $U_{3}=(10,5)$ & $U_{3}=(10,5)$ \\
\hline
\end{tabular}

Table 4. Subjacent and nonsubjacent components' inflation

\begin{tabular}{ccccc}
\hline Date & $\begin{array}{c}\text { CPI } \\
\text { Merchandise }\end{array}$ & CPI Services & $\begin{array}{c}\text { CPI } \\
\text { Agricultural }\end{array}$ & $\begin{array}{c}\text { CPI Energetics } \\
\text { and } \\
\text { government }\end{array}$ \\
\hline $01-17$ & 0.9278 & 0.2813 & -0.8827 & 8.9611 \\
$02-17$ & 1.1050 & 0.4717 & -0.9389 & 0.5906 \\
$03-17$ & 0.7765 & 0.3967 & 2.1955 & -0.0958 \\
$04-17$ & 0.6045 & 0.3157 & 1.8729 & -2.4197 \\
$05-17$ & 0.4794 & 0.0977 & 1.2060 & -2.8203
\end{tabular}




\begin{tabular}{ccccc}
$06-17$ & 0.3163 & 0.2939 & 0.4233 & -0.1210 \\
$07-17$ & 0.1173 & 0.3993 & 2.4874 & -0.4099 \\
$08-17$ & 0.4728 & 0.0633 & 2.0606 & 0.6736 \\
$09-17$ & 0.3296 & 0.2408 & -0.0624 & 0.7152 \\
$10-17$ & 0.2155 & 0.2848 & -1.8811 & 4.1530 \\
$11-17$ & 0.3357 & 0.3518 & 1.1611 & 4.2378 \\
$12-17$ & 0.3231 & 0.5028 & 1.8128 & 0.6533 \\
\hline
\end{tabular}

Step 4. Using the traditional formulas, OWAI operator and its extensions the subjacent and nonsubjacent inflation is calculated (See Table 5 and Table 6). It is important to note that in this step the different cases of the OWAI operator can be applied (See section 3.3 and Table $1)$.

Step 5. With the results of the subjacent and nonsubjacent inflation presented in Table 5 and Table 6, the next step is to determine the weights that will be used to calculate the monthly inflation. In this case, the weights provided general formulation are used (See Definition 1) but also, each expert provided different set of weights according to their knowledge and expectations (See Table 7).

Table 7. Weights assigned to inflation

\begin{tabular}{|l|l|}
\hline Expert & Weights for inflation \\
\hline$e_{1}$ & $W_{1}=(0.70,0.30), H_{1}=(0.70,0.40), U_{1}=(5,10)$ \\
\hline$e_{2}$ & $W_{2}=(0.80,0.20), H_{2}=(0.80,0.30), U_{2}=(5,10)$ \\
\hline$e_{3}$ & $W_{3}=(0.60,0.40), H_{3}=(0.65,0.45), U_{3}=(5,10)$ \\
\hline
\end{tabular}

Table 5. Subjacent inflation

\begin{tabular}{cc|c|c|c|c|c|c|c|c|}
\hline & & \multicolumn{5}{c|}{ Expert 1 } & \multicolumn{4}{c|}{ Expert 2 } \\
\hline Date & Traditional & OWAI & IOWAI & HOWAI & IHOWAI & OWAI & IOWAI & HOWAI & IHOWAI \\
\hline $\mathbf{0 1 - 1 7}$ & 0.5852 & 0.5722 & 0.6369 & 0.6327 & 0.6973 & 0.5399 & 0.6692 & 0.5680 & 0.7620 \\
$\mathbf{0 2 - 1 7}$ & 0.7694 & 0.7567 & 0.8201 & 0.8356 & 0.8989 & 0.7251 & 0.8517 & 0.7722 & 0.9622 \\
$\mathbf{0 3 - 1 7}$ & 0.5752 & 0.5676 & 0.6056 & 0.6263 & 0.6642 & 0.5486 & 0.6246 & 0.5883 & 0.7022 \\
$\mathbf{0 4 - 1 7}$ & 0.4514 & 0.4456 & 0.4745 & 0.4916 & 0.5205 & 0.4312 & 0.4890 & 0.4628 & 0.5494 \\
$\mathbf{0 5 - 1 7}$ & 0.2771 & 0.2695 & 0.3077 & 0.2983 & 0.3365 & 0.2504 & 0.3267 & 0.2602 & 0.3747
\end{tabular}




\begin{tabular}{ccccccccccc}
$\mathbf{0 6 - 1 7}$ & 0.3045 & 0.3040 & 0.3063 & 0.3345 & 0.3368 & 0.3029 & 0.3074 & 0.3323 & 0.3390 \\
$\mathbf{0 7 - 1 7}$ & 0.2668 & 0.2724 & 0.2442 & 0.2982 & 0.2700 & 0.2865 & 0.2301 & 0.3264 & 0.2418 \\
$\mathbf{0 8 - 1 7}$ & 0.2558 & 0.2476 & 0.2885 & 0.2744 & 0.3153 & 0.2271 & 0.3090 & 0.2334 & 0.3563 \\
$\mathbf{0 9 - 1 7}$ & 0.2825 & 0.2808 & 0.2896 & 0.3093 & 0.3182 & 0.2763 & 0.2941 & 0.3004 & 0.3270 \\
$\mathbf{1 0 - 1 7}$ & 0.2522 & 0.2536 & 0.2467 & 0.2786 & 0.2717 & 0.2571 & 0.2432 & 0.2856 & 0.2648 \\
$\mathbf{1 1 - 1 7}$ & 0.3442 & 0.3446 & 0.3429 & 0.3789 & 0.3773 & 0.3454 & 0.3421 & 0.3805 & 0.3757 \\
$\mathbf{1 2 - 1 7}$ & 0.4183 & 0.4219 & 0.4040 & 0.4632 & 0.4452 & 0.4309 & 0.3950 & 0.4812 & 0.4273 \\
\hline \multicolumn{8}{c}{ Expert 3 } & \multicolumn{10}{c|}{ 3rioritized } \\
\hline Date & OWAI & IOWAI & HOWAI & IHOWAI & POWAI & PIOWAI & PHOWAI & PIHOWA \\
\hline $\mathbf{0 1 - 1 7}$ & 0.6239 & 0.5852 & 0.6509 & 0.6186 & 0.5848 & 0.6243 & 0.6238 & 0.6820 \\
$\mathbf{0 2 - 1 7}$ & 0.8074 & 0.7694 & 0.8436 & 0.8120 & 0.7691 & 0.8077 & 0.8230 & 0.8800 \\
$\mathbf{0 3 - 1 7}$ & 0.5980 & 0.5752 & 0.6254 & 0.6064 & 0.5750 & 0.5982 & 0.6164 & 0.6506 \\
$\mathbf{0 4 - 1 7}$ & 0.4687 & 0.4514 & 0.4903 & 0.4759 & 0.4513 & 0.4689 & 0.4839 & 0.5099 \\
$\mathbf{0 5 - 1 7}$ & 0.3000 & 0.2771 & 0.3125 & 0.2935 & 0.2769 & 0.3002 & 0.2945 & 0.3288 \\
$\mathbf{0 6 - 1 7}$ & 0.3058 & 0.3045 & 0.3209 & 0.3198 & 0.3044 & 0.3058 & 0.3285 & 0.3305 \\
$\mathbf{0 7 - 1 7}$ & 0.2498 & 0.2668 & 0.2642 & 0.2783 & 0.2669 & 0.2497 & 0.2917 & 0.2663 \\
$\mathbf{0 8 - 1 7}$ & 0.2803 & 0.2558 & 0.2917 & 0.2712 & 0.2556 & 0.2805 & 0.2711 & 0.3079 \\
$\mathbf{0 9 - 1 7}$ & 0.2879 & 0.2825 & 0.3017 & 0.2972 & 0.2825 & 0.2879 & 0.3040 & 0.3120 \\
$\mathbf{1 0 - 1 7}$ & 0.2481 & 0.2522 & 0.2609 & 0.2644 & 0.2523 & 0.2480 & 0.2733 & 0.2671 \\
$\mathbf{1 1 - 1 7}$ & 0.3433 & 0.3442 & 0.3605 & 0.3613 & 0.3442 & 0.3433 & 0.3720 & 0.3705 \\
$\mathbf{1 2 - 1 7}$ & 0.4075 & 0.4183 & 0.4291 & 0.4381 & 0.4184 & 0.4075 & 0.4541 & 0.4379 \\
\hline
\end{tabular}

Table 6. Nonsubjacent inflation

\begin{tabular}{cc|c|c|c|c|c|c|c|c|}
\hline & & \multicolumn{5}{|c|}{ Expert 1 } & \multicolumn{4}{c|}{ Expert 2 } \\
\hline Date & Traditional & OWAI & IOWAI & HOWAI & IHOWAI & OWAI & IOWAI & HOWAI & IHOWAI \\
\hline $\mathbf{0 1 - 1 7}$ & 5.3189 & 5.0236 & 3.0548 & 5.4275 & 3.4587 & 4.5314 & 3.5470 & 4.9353 & 3.9509 \\
$\mathbf{0 2 - 1 7}$ & 0.0247 & -0.0212 & -0.3271 & -0.0386 & -0.3445 & -0.0977 & -0.2506 & -0.1151 & -0.2680 \\
$\mathbf{0 3 - 1 7}$ & 0.7520 & 0.8207 & 1.2790 & 0.9257 & 1.3840 & 0.9353 & 1.1644 & 1.0403 & 1.2694 \\
$\mathbf{0 4 - 1 7}$ & -0.8314 & -0.7027 & 0.1559 & -0.7300 & 0.1285 & -0.4880 & -0.0588 & -0.5154 & -0.0861
\end{tabular}




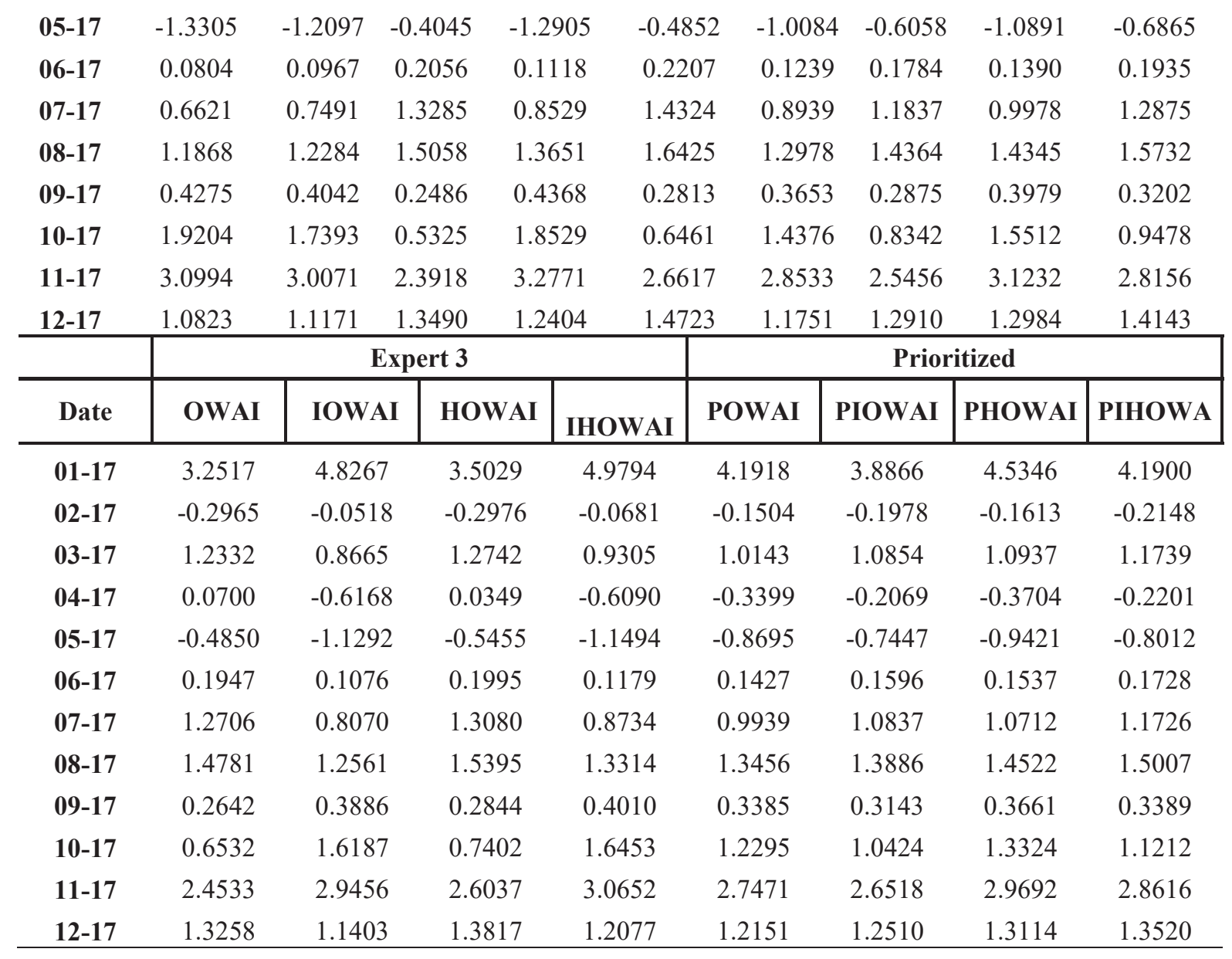

Step 6. In this step the calculation of the monthly and annual inflation is done. To do this, the traditional formulation, the OWAI operator and its extension are used. The results are presented in Table 8.

Table 8. Mexico Inflation for 2017

\begin{tabular}{lc|c|c|c|c|c|c|c|c}
\hline & & \multicolumn{4}{c|}{ Expert 1 } & \multicolumn{4}{c}{ Expert 2 } \\
\hline Date & Traditional & OWAI & IOWAI & HOWAI & IHOWAI & OWAI & IOWAI & HOWAI & IHOWAI \\
\hline $01-17$ & 1.7686 & 1.9076 & 2.3294 & 2.6139 & 2.7000 & 1.3382 & 2.9714 & 1.9350 & 3.3893 \\
$02-17$ & 0.5832 & 0.5234 & 0.0171 & 0.5695 & 0.1184 & 0.5605 & -0.0301 & 0.5833 & 0.0742 \\
$03-17$ & 0.6194 & 0.6435 & 1.0770 & 0.8087 & 1.2345 & 0.6260 & 1.0564 & 0.7827 & 1.2262
\end{tabular}




\begin{tabular}{|c|c|c|c|c|c|c|c|c|c|}
\hline $04-17$ & 0.1307 & 0.1011 & 0.2515 & 0.0522 & 0.2982 & 0.2473 & 0.0508 & 0.2156 & 0.0959 \\
\hline $05-17$ & -0.1248 & -0.1743 & -0.1908 & -0.3073 & -0.2050 & -0.0014 & -0.4193 & -0.1186 & -0.4368 \\
\hline $06-17$ & 0.2484 & 0.2418 & 0.2358 & 0.2789 & 0.2892 & 0.2671 & 0.2042 & 0.3075 & 0.2565 \\
\hline $07-17$ & 0.3656 & 0.4154 & 1.0032 & 0.5499 & 1.1107 & 0.4080 & 0.9929 & 0.5605 & 1.1026 \\
\hline $08-17$ & 0.4885 & 0.5418 & 1.1406 & 0.7381 & 1.2759 & 0.4412 & 1.2110 & 0.6171 & 1.3654 \\
\hline $09-17$ & 0.3188 & 0.3178 & 0.2609 & 0.3912 & 0.3242 & 0.2941 & 0.2888 & 0.3597 & 0.3542 \\
\hline $10-17$ & 0.6693 & 0.6993 & 0.4468 & 0.9362 & 0.5610 & 0.4932 & 0.7160 & 0.6938 & 0.8377 \\
\hline $11-17$ & 1.0330 & 1.1433 & 1.7771 & 1.5761 & 2.0141 & 0.8470 & 2.1049 & 1.2414 & 2.3652 \\
\hline $12-17$ & 0.5843 & 0.6305 & 1.0655 & 0.8204 & 1.2087 & 0.5797 & 1.1118 & 0.7744 & 1.2596 \\
\hline Anual & 6.6851 & 6.9913 & 9.4140 & $\mathbf{9 . 0 2 7 7}$ & 10.9298 & 6.1010 & 10.2589 & 7.9525 & 11.8901 \\
\hline \multirow[b]{2}{*}{ Date } & \multicolumn{4}{|c|}{ Expert 3} & \multicolumn{5}{|c|}{ Prioritized } \\
\hline & OWAI & IOWAI & HOWAI & IHOWAI & POWAI & PIO & VAI & PHOWAI & PIHOWA \\
\hline 01-17 & 1.6750 & 3.1301 & 1.9994 & 3.5150 & 1.6722 & & & 2.1984 & 3.1983 \\
\hline 02-17 & 0.3658 & 0.2767 & 0.4145 & 0.3211 & 0.4696 & & & 0.5109 & 0.1884 \\
\hline 03-17 & 0.8521 & 0.7500 & 0.9799 & 0.8777 & 0.7226 & & & 0.8707 & 1.0897 \\
\hline 04-17 & 0.3092 & -0.1895 & 0.3344 & -0.1817 & 0.2209 & & & 0.2059 & 0.0557 \\
\hline 05-17 & -0.0140 & -0.5667 & -0.0423 & -0.6151 & -0.0669 & -0.3 & & -0.1542 & -0.4270 \\
\hline 06-17 & 0.2614 & 0.1863 & 0.2984 & 0.2205 & 0.2560 & 0.2 & & 0.2939 & 0.2536 \\
\hline 07-17 & 0.6581 & 0.5909 & 0.7603 & 0.6929 & 0.5106 & 0.8 & & 0.6367 & 0.9416 \\
\hline 08-17 & 0.7594 & 0.8560 & 0.8824 & 0.9875 & 0.6037 & 1.0 & & 0.7656 & 1.1829 \\
\hline 09-17 & 0.2784 & 0.3462 & 0.3241 & 0.3944 & 0.2961 & 0.3 & & 0.3565 & 0.3598 \\
\hline $10-17$ & 0.4101 & 1.0721 & 0.5027 & 1.1884 & 0.5321 & 0.7 & & 0.7022 & 0.8811 \\
\hline $11-17$ & 1.1873 & 1.9050 & 1.4060 & 2.1550 & 1.0868 & 1.9 & & 1.4244 & 2.1582 \\
\hline $12-17$ & 0.7748 & 0.8515 & 0.9007 & 0.9822 & 0.6755 & 0.9 & & 0.8410 & 1.1308 \\
\hline Anual & 7.5178 & 9.2086 & 8.7603 & 10.5380 & 6.9793 & 9.5 & & 8.6519 & 11.0131 \\
\hline
\end{tabular}

As seen in Table 8, the annual inflation in Mexico depending on the aggregation operator that is used can range from 6.1010 for OWAI expert 2 to 11.8901 for IHOWA expert 3 . This information is important because inflation is an important economic factor for each country. In Mexico, it is possible to see that the traditional annual inflation for 2017 of 6.6851 can change drastically depending on the weights of the components that integrate the inflation change and it can go as high as 11.8901. In this sense, it is possible that if the formulation that is used in order to calculate the inflation change using the official information that the INEGI reports is not accurate, then the general inflation of the country could be lower or higher. This information is important for the enterprises, governments, investors and people in general because many politics like minimum salaries, for example, are based on this information. That is why the introduction of these operators in classical economic formulations can provide new scenarios that before could not be addressed and doing this allows for better decisions in a country. 
From the economic point of view, the introduction of these operators is important because inflation can be dynamic and different numbers can be obtained based on different criteria. Additionally, by doing this exercise, it is possible to better understand the reality of certain sectors or regions where inflation is perceived by people to be much higher (or lower) than that reported by the Central Bank. This information can improve the public policies and decisions that are made by governments and provide a more comprehensive view of the situations that are happening.

Finally, the weighting, induced and prioritized vectors, such as the one's presented in Table 3 and Table 7, are an important element because the used of different numbers can drastically change the results. In the example provided in this article, a questionnaire has been done to each expert asking them about the importance of the elements that compose the subjacent and nonsubjacent and another one asking them about the importance of the subjacent and nonsubjacent inflation to the monthly inflation.

As can be seen, in this article we didn't use any specific technique such as minimal variability or disparity approach [29-31] or any other related technique to determine the weights but decided to let the experts decided the weights without any restriction. This can be one of the main advantages or disadvantages of the technique. For one side, it is possible to easily generate different scenarios through the changes in the weighting vector but in other hand, is hard to obtain a unified result or even pick one scenario as the best one. In this sense, one technique that can be used to get the information from the experts is the linguistic representations models [32-33].

For last, it is important to note that the government has its own weights for calculate monthly and annual inflation and in this paper, we present how much the inflation can change based on expert's information. This idea is important because usually the information provided by the government is not always the best for the decision-making process in enterprises. That is why, using these techniques can provided a better and wider view of the reality of the companies

\section{Conclusions}

The objective of the paper is to provide a new formulation in order to calculate the important economic variable of inflation. These formulations were made using the ordered weighted average (OWA) operator as a base and its extension, the prioritized induced heavy ordered weighted average (PIHOWA) operator. The most important characteristics of these new formulations are that they can change the weights of the components of the subjacent and nonsubjacent inflation formulas and the way that both are integrated in the general inflation formula using heavy weighting vectors and induced variables. In addition, they can integrate the information that is provided by different experts. 
In the paper, a particular case for Mexico's inflation has been analyzed. Additionally, as seen in section 3.3, there are some special cases that can be applied if the aggregation operators are used in all the elements of the formulation or if they are only used in the subjacent or nonsubjacent inflation formulas. This information is important because the weights that are associated with each of the components can change monthly or annually according to the importance that each one has, and in that way, new inflation scenarios can be generated.

An example of Mexico's 2017 inflation is also presented. From the results, it is possible to see that the inflation can range from 6.1010 to 11.8901 depending on the expert and the aggregation operator that it is used, which is different from the 6.6851 that is obtained using the traditional formulation. As can be noted, these new inflation scenarios can help to generate new political, enterprise and personal decisions because inflation is now a range and not a set number, which can provide a better understanding of the economic situation of a country.

For future research, new extensions of the OWA operator [34] can be done using Bonferroni Means [23-24], multicriteria decision making [25-27] and applications in other areas such as statistics, mathematics, economics, finance, innovation and any other related field.

\section{References}

[1]. Friedman, M. (1977). Nobel lecture: inflation and unemployment. Journal of Political Economy, 85(3), 451-472.

[2]. Grier, K. B., \& Perry, M. J. (2000). The effects of real and nominal uncertainty on inflation and output growth: some garch- m evidence. Journal of Applied Econometrics, $15(1), 45-58$.

[3]. Vlandas, T. (2018). Grey power and the Economy: Aging and Inflation Across Advanced Economies. Comparative Political Studies, 51(4), 514-552.

[4]. Judson, R., \& Orphanides, A. (1999). Inflation, volatility and growth. International Finance, 2(1), 117-138.

[5]. Levine, R., \& Renelt, D. (1992). A sensitivity analysis of cross-country growth regressions. The American Economic Review, 942-963.

[6]. Hineline, D. R. (2007). Examining the robustness of the inflation and growth relationship. Southern Economic Journal, 1020-1037.

[7]. Eggoh, J. C., \& Khan, M. (2014). On the nonlinear relationship between inflation and economic growth. Research in Economics, 68(2), 133-143.

[8]. Moore, D., \& Fraser, S. (2015). Causation, knowledge and politics: Greater precision and rigour needed in methamphetamine research and policy-making to avoid problem inflation. Addiction Research \& Theory, 23(2), 89-92. 
[9]. Svensson, L. E. (2000). Open-economy inflation targeting. Journal of International Economics, 50(1), 155-183.

[10]. G. Antinolfi, C. Azariadis, J. Bullard, The optimal inflation target in an economy with limited enforcement. Macroeconomic Dynamics, 20(2), (2016), 582-600.

[11]. Brunnermeier, M. K., \& Sannikov, Y. (2016). On the optimal inflation rate. American Economic Review, 106(5), 484-89.

[12]. Yager, R. R. (1988). On ordered weighted averaging aggregation operators in multicriteria decisionmaking. IEEE Transactions on Systems, Man, and Cybernetics, 18(1), 183-190.

[13]. He, X.R., Wu, Y.Y., Yu, D., \& Merigó, J.M. (2017). Exploring the ordered weighted averaging operator knowledge domain: A bibliometric analysis. International Journal of Intelligent Systems, 32, 1151-1166.

[14]. Yager, R. R., \& Filev, D. P. (1999). Induced ordered weighted averaging operators. IEEE Transactions on Systems, Man, and Cybernetics, Part B (Cybernetics), 29(2), 141150.

[15]. Yager, R. R. (2002). Heavy OWA operators. Fuzzy Optimization and Decision Making, 1(4), 379-397.

[16]. Yager, R. R. (2009). Prioritized OWA aggregation. Fuzzy Optimization and Decision Making, 8(3), 245-262.

[17]. Doña, J. M., David, L., \& Peláez, J. I. (2009). A mix model of discounted cash-flow and OWA operators for strategic valuation. International Journal of Interactive Multimedia and Artificial Intelligence, 1(2), 20-25.

[18]. Leon-Castro, E., Avilés-Ochoa, E. A., \& Gil-Lafuente, A. M. (2016). Exchange rate USD/MXN forecast through econometric models, time series and HOWMA operators. Economic Computation \& Economic Cybernetics Studies \& Research, 50(4), 135-150.

[19]. León-Castro, E., Avilés-Ochoa, E., Merigó, J.M., \& Gil-Lafuente, A.M. (2018). Heavy moving averages and their application in econometric forecasting. Cybernetics \& Systems, 49, 26-43.

[20]. Merigó, J.M., Palacios-Marqués, D., \& Benavides, M. (2015). Aggregation methods to calculate the average price. Journal of Business Research, 68, 1574-1580.

[21]. F. Blanco-Mesa, E. León-Castro, J.M. Merigó, J. M., Bonferroni induced heavy operators in ERM decision-making: A case on large companies in Colombia. Applied Soft Computing, 72, (2018), 371-391.

[22]. INEGI (2018). National Institute of Statistic and Geography, Consumer Price Index, http://www.beta.inegi.org.mx/proyectos/precios/inpc/

[23]. Blanco-Mesa, F., León-Castro, E., \& Merigó, J. M. (2019). Bonferroni means with induced ordered weighted average operators. International Journal of Intelligent Systems, 34(1), 3-23.

[24]. Liu, P., \& Liu, J. (2018). Some q- rung orthopai fuzzy Bonferroni mean operators and their application to multi- attribute group decision making. International Journal of Intelligent Systems, 33(2), 315-347.

[25]. Liu, P. (2014). Some Hamacher aggregation operators based on the interval-valued intuitionistic fuzzy numbers and their application to group decision making. IEEE Transactions on Fuzzy Systems, 22(1), 83-97.

[26]. Liu, P., Chen, S. M., \& Wang, P. (2018). Multiple-attribute group decision-making based on q-rung orthopair fuzzy power maclaurin symmetric mean operators. IEEE Transactions on Systems, Man, and Cybernetics: Systems, (99), 1-16. 
[27]. Liu, P., \& Tang, G. (2018). Some Intuitionistic Fuzzy Prioritized Interactive Einstein Choquet Operators and Their Application in Decision Making. IEEE Access, 6, 72357-72371.

[28]. Afshari, A., Mojahed, M., \& Yusuff, R. M. (2010). Simple additive weighting approach to personnel selection problem. International Journal of Innovation, Management and Technology, 1(5), 511.

[29]. Wang, Y. M., \& Parkan, C. (2005). A minimax disparity approach for obtaining OWA operator weights. Information Sciences, 175(1-2), 20-29.

[30]. Fullér, R., \& Majlender, P. (2003). On obtaining minimal variability OWA operator weights. Fuzzy Sets and Systems, 136(2), 203-215.

[31]. Wang, Y. M., Luo, Y., \& Liu, X. (2007). Two new models for determining OWA operator weights. Computers \& Industrial Engineering, 52(2), 203-209.

[32]. Herrera, F., \& Martínez, L. (2000). A 2-tuple fuzzy linguistic representation model for computing with words. IEEE Transactions on Fuzzy Systems, 8(6), 746-752.

[33]. Herrera, F., \& Herrera-Viedma, E. (2000). Linguistic decision analysis: steps for solving decision problems under linguistic information. Fuzzy Sets and Systems, 115(1), 67-82.

[34]. Kacprzyk, J., Yager, R. R., \& Merigó, J. M. (2019). Towards human centric aggregation via the ordered weighted aggregation operators and linguistic data summaries: A new perspective on Zadeh's inspirations. IEEE Computational Intelligence Magazine, 14(1) (2019) 16-30.

[35]. Avilés-Ochoa, E. León-Castro, L.A. Perez-Arellano, J.M. Merigó, Government transparency measurement through prioritized distance operators. Journal of Intelligent \& Fuzzy Systems, 34 (4), (2018), 2783-2794. 